\title{
Súmula Vinculante: Uma Análise à Luz do Princípio da Separação dos Poderes e do Livre Convencimento e Independência do Juiz
}

\author{
RAFAELA LIMA TEIXEIRA \\ Aluna da FA7, orientada pelo prof. Jânio Nunes Vidal. \\ rafaelalimat@hotmail.com
}

Sumário: 1) Introdução; 2) Separação dos poderes; 3) Poder Judiciário, as leis e a função interpretativa; 4) Súmula vinculante; 5) Súmula vinculante e o livre convencimento e independência do juiz; 6) Súmula vinculante e a separação dos poderes; 7) Considerações finais; 8) Referências bibliográficas.

Resumo: O presente estudo analisou a súmula vinculante à luz do princípio da separação dos poderes e do livre convencimento e independência do juiz. Para tanto, apresentaram-se os termos em que a súmula vinculante foi aprovada e se mostrou que o moderno entendimento do princípio da tripartição dos poderes acolhe o exercício da atípica atividade legislativa por parte do Poder Judiciário em razão da finalidade do instituto, qual seja, a prestação jurisdicional isonômica e eficaz. Será pontuada que a atividade judiciária envolve a interpretação da norma legal, e que a interpretação vinculante do Supremo Tribunal Federal não retira toda a independência e o livre convencimento do juiz, dado que lhe caberá, no julgamento do caso concreto, verificar se existem particularidades que determinam a aplicação da súmula ou seu afastamento motivado. O livre convencimento e a independência do juiz podem ser relativizados em prol da garantia de isonomia para os destinatários da atividade jurisdicional. Ressalta-se que a interpretação conferida pelo STF à norma corresponderá a melhor interpretação possível em consonância com a Constituição Federal, e não parece excesso da Corte Suprema vincular seu entendimento aos demais órgãos judiciais e à administração.

Palavras-chave: Súmula vinculante. Tripartição dos poderes. Livre convicção e independência do juiz. 


\section{CO INTRODUÇÃO}

A súmula vinculante foi recentemente inserida no contexto jurídico brasileiro através da Emenda Constitucional n. 45/04, denominada Reforma do Judiciário.

A referida reforma ambientou-se em um momento marcado pela justiça brasileira que encontrava-se sobrecarregada com o grande número de processos em tramitação, pela crise judiciária instalada no país em decorrência da ineficácia da prestação judicial, diante de sua lentidão e pelos julgamentos de casos iguais culminarem em sentenças distintas, variando em função da região, vara, câmara ou seção que as efetuou.

A súmula vinculante foi apresentada como um dos instrumentos para sanar esses problemas enfrentados pelo sistema jurisdicional brasileiro.

Entretanto, enorme discussão doutrinária envolve este instituto. Sua constitucionalidade é amplamente questionada, sendo apontado contra este preceito judicial ofensa ao princípio da legalidade, restrição à livre convicção e independência do julgador, cerceamento do direito ao acesso ao judiciário, o desrespeito à separação dos poderes e a paralisação da evolução do direito brasileiro, que tem como uma de suas molas propulsoras a divergência existente na interpretação das leis pelos juízes.

Por outro lado, posições doutrinárias a favor se fundamentam na isonomia processual e na segurança jurídica.

Não cabe neste trabalho esgotar todas as discussões sobre o tema. O enfoque do presente estudo será a análise da súmula vinculante à luz do princípio da separação dos poderes e da livre convicção e independência do julgador, com a utilização da metodologia do estudo bibliográfico.

Breves considerações históricas acerca do princípio da separação dos poderes serão apresentadas, buscando demonstrar a evolução do entendimento deste princípio até a sua moderna compreensão, tudo para tornar possível uma análise crítica da súmula vinculante face à tripartição dos poderes.

A função do Poder Judiciário, na aplicação da norma, também será debatida, discutindo se o ato jurídico é meramente declaratório ou se é possível criar o direito.

O instituto da súmula vinculante será exposto, demonstrando o seu funcionamento e sua viabilidade no sistema romano-germânico adotado no Brasil dominado pela primazia da lei.

Mostrar-se-á em que a súmula limita os juízes e se esta limitação impede seu livre convencimento.

Ao final, espera-se restar comprovado que a súmula vinculante não afronta o princípio da separação dos poderes e o livre convencimento e independência dos juízes 


\section{$\infty$ Separação dos Poderes}

A teoria da separação dos poderes, consagrada por Montesquieu, surgiu como uma forma de conter o absolutismo do governo à época. A arbitrariedade com que os governantes agiam tinha respaldo na concentração de poderes nas mãos de uma única pessoa ou um pequeno grupo, o que ocasionava o completo desrespeito às liberdades individuais. No dizer do referido autor, que fora citado pelo jurista Dalmo Dallari, quando na mesma pessoa o Poder Legislativo está reunido ao Poder Executivo, não há liberdade; falta a confiança por se temer que esse monarca ou esse senado faça leis tirânicas para executá-las tiranicamente. (2005, p.215)

Por essa teoria, destacava-se a necessidade de que os Poderes Executivo, Legislativo e Judiciário fossem exercidos por órgãos distintos, harmônicos e independentes entre si.

Importante ressaltar que o momento histórico (Séc. XVIII) de consolidação da teoria correspondia à ascensão da burguesia ao poder, que convergia suas forças na tentativa de enfraquecer o poder da nobreza para garantir uma maior liberdade individual.

Dessa forma, conforme assevera Dalmo de Abreu Dallari, inicialmente, o fim exclusivo da teoria da separação dos poderes era a proteção da liberdade e apenas mais tarde o objetivo foi estendido para o aumento da eficiência do Estado, pela distribuição de suas atribuições entre órgãos especializados (2003, p.215).

Modernamente, a complexidade das relações sociais exigiu que a separação dos poderes fosse vista com temperamentos. Os poderes não são compartimentos estanques, permitindo o exercício de atos de competência dos demais justamente para garantir uma maior eficiência ao Estado e proteção aos direitos dos particulares.

Salienta Alexandre de Moraes sobre o moderno entendimento do princípio da separação dos poderes, in litteris:

O Direito Constitucional contemporâneo, apesar de permanecer na tradicional linha da idéia da Tripartição dos Poderes, já entende que esta fórmula, se interpretada com rigidez, tornou-se inadequada para um Estado que assumiu a missão de fornecer a todo o seu povo o bem-estar, devendo, pois, separar as funções estatais, dentro de um mecanismo de controle recíprocos, denominado "freios e contrapesos” (checks and balances). (2003, p. 373)

Assim, dispôs a Carta Magna brasileira, que conferiu a possibilidade do exercício atípico de funções dos outros poderes.

Exemplificando, o Executivo, consubstanciado pelo Presidente da República nesta competência, pode, em caso de relevância e urgência, adotar medidas provisórias com força de lei, praticando atos de atribuição técnica do Legislativo. 
Caso contrário, a excessiva lentidão e morosidade legislativa, ao qual o Executivo estaria subordinado, traria substanciais prejuízos à sociedade.

\section{\. Poder JUdiCiÁRIO, AS LEIS E A FUNÇÃo INTERPRETATIVA}

O Poder Judiciário tem como função típica a jurisdicional. Ao lhe ser apresentado um conflito de interesses na sociedade, aplica-se, para resolução da lide, a norma ao caso concreto.

Primeiramente, convém tecer algumas observações acerca das leis e da legitimidade democrática do Poder Legislativo:

A competência para a elaboração das normas jurídicas é conferida prioritariamente ao Poder Legislativo. Os legisladores são representantes do povo, eleitos periódica e diretamente, o que dá legitimidade para que confeccionem as regras que restringirão as liberdades individuais, em prol de possibilitar o convívio em sociedade.

A legitimidade que o sufrágio lhes imprime, aliada ao fato de as leis constituírem normas gerais e abstratas, dirigidas a um número indeterminado de pessoas, não se podendo saber previamente a quem irão atingir, confere às leis elaboradas pelo Poder Legislativo uma certeza e segurança para convivência social, permitindo a liberdade e garantindo um tratamento igualitário, muito embora apenas formalmente, entre os homens (Vidal, 2005, p. 19).

Quando ocorre violação da lei, abre possibilidade para o particular lesado ajuizar uma ação no Poder Judiciário para requerer o seu cumprimento.

O Poder Judiciário, contudo, não possui o caráter de representatividade do povo, por não ser por este eleito, sendo impossível a sua criação do direito. Este é um forte argumento levantado pela corrente doutrinária que defende que o juiz, no ato de aplicação da norma, não poderá interpretá-la, pois se dessa forma agisse, estaria criando o direito.

Sobre a atividade julgadora do Poder Judiciário, Álvaro Cruz afirma:

a teoria da separação dos poderes trouxe consigo uma concepção própria para uma teoria da decisão judicial. Enquanto a legislação traduzia-se por um ato de vontade do povo, por meio de seus representantes, a decisão judicial traduzia-se por um ato de ciência, um ato de cognição da vontade do legislador. O Judiciário, ao decidir, deveria simplesmente aplicar ao caso concreto uma decisão política fixada anteriormente pelo legislador. Seu ato seria neutro politicamente. A aplicação do Direito deveria ser despida de qualquer preferência pessoal do julgador, vez que lhe incumbia apenas conhecer os valores impostos por quem lhe teria legitimidade para tanto. (Vidal, 2005, p. 19) 
Por tal entendimento, o juiz deveria aplicar a lei da forma que ela foi formulada, sem lhe ser possível interpretá-la, devendo apenas declarar a vontade do legislador, sob pena de conflitar com o princípio da separação dos poderes.

Hans Kelsen discorda ser a atividade do juiz meramente declaratória, posto que a lei apenas define parâmetros gerais. "A norma geral é sempre uma simples moldura dentro da qual há de ser produzida a norma jurídica individual.” (2000, p.272)

Essa norma jurídica individual, para ser produzida, precisa passar pela via interpretativa do aplicador do direito, uma vez que as particularidades que se constatam no caso concreto não foram expressamente regulamentadas na norma legal. Assim pensa David Schnaid, que afirma que “ a raiz latina - inter - da palavra indica que o intérprete se coloca 'entre' o ordenamento jurídico e os fatos que lhe são apresentados.” (2004, p. 272) Este doutrinador explica que quando o hermeneuta vai aplicar o direito, a situação sobre a qual será proferida o julgamento normalmente não se apresenta como na previsão normativa, necessitando-se, assim, adaptar a legislação existente ou criar a norma individual.

Caso houvesse concordância com a corrente que defende que o ato judicial é meramente declaratório, estaria afirmando ser imprescindível que o legislador previsse todos os dissídios que pudessem surgir na sociedade.

As inimagináveis particularidades de cada caso obrigam o legislador a emitir normas gerais e abstratas, para atingir um número indeterminado de situações. Entretanto, devido à infinita diversidade de situações que ocorrem no cotidiano, por vezes acontece do fato não ter sido abrangido diretamente por lei alguma. Ocorre que, pelo art. 5, XXXV, o Poder Judiciário não pode deixar de apreciar lesão ou ameaça a direito, independente de no ordenamento jurídico estar prevista diretamente sua solução.

Tal entendimento poderia obstacularizar a atividade judiciária na resolução dos conflitos na sociedade.

Sobre o ordenamento jurídico, diz Schnaid:

As leis e, em geral, todas as normas jurídicas, são elaboradas para serem complementadas pela interpretação, pois em caso contrário far-se-ia necessário um número inimaginável de normas extremamente complexas e tediosas e, ainda assim, estaria incompleto. (2004, p.272)

O juiz, ao deparar-se com um caso em que não há uma lei que regulamente a situação apresentada, não poderá, contudo, agir discricionariamente. O intérprete irá procurar a solução dos conflitos dentro da ordem jurídica, pois o ordenamento jurídico é considerado completo, configurando esta plenitude uma garantia contra a subjetividade do juiz. Aparentes lacunas deverão ser preenchidas por princípios gerais do direito, por analogia e pelo direito consuetudinário. 
Para solução de casos concretos em que há leis ou princípios conflitantes, precisará o jurista realizar uma ponderação das normas, para se extrair a melhor solução.

Nesse diapasão, colaciona-se a doutrina de Carlos Cóssio, citada por David Schnaid não se interpreta a norma, uma lei. Extrai-se a regra a aplicar, de todo o ordenamento jurídico, como uma totalidade sistematicamente estruturada, em face do caso concreto. (2004, p. 274)

\section{Súmula Vinculante}

Da pacificação sobre a possibilidade de o juiz criar direito ao aplicar a norma ao caso concreto, descortina-se o ponto fundamental do trabalho: o direito criado poderá ter efeitos gerais tal como se confere a norma legal criada pelo Poder Legislativo ou a natureza geral da súmula vinculante afronta o princípio da separação dos poderes? A obrigatoriedade de adotar-se a interpretação estabelecida pela súmula limita o livre convencimento e a independência do juiz?

O sistema jurídico brasileiro foi influenciado pelo direito europeu e filiouse à família romano-germânica, em cujo sistema há a prevalência do processo legislativo. Em outra vertente, encontram-se os ordenamentos jurídicos de tradição anglo-americana, em que o direito aparece principalmente em decorrência dos usos e costumes e da jurisdição do que pela atividade legiferante.

A respeito da diferenciação dos sistemas jurídicos em common law e em civil law, Kelsen diz:

a teoria, nascida no terreno da common law anglo-americana, segundo a qual somente os tribunais criam o Direito, é tão unilateral como a teoria, nascida no terreno do Direito legislado da Europa continental, segundo a qual os tribunais não criam de forma alguma Direito, mas apenas aplicam o Direito já criado. Esta teoria implica a idéia de que só há normas jurídicas gerais, aquela implica a de que só há normas jurídicas individuais. A verdade está no meio (2000, p.283)

Realmente tem-se observado nos últimos anos uma maior aproximação entre os dois sistemas, seja pela promulgação de leis pelos países filiados ao common law, seja pela maior importância conferida aos precedentes judiciais no direito de tradição romanística. O conferimento de status vinculante as súmulas proferidas pelo Supremo Tribunal Federal denota a relativização do dogma da supremacia do parlamento presente em nossa ordenação.

A súmula vinculante tem como pressupostos de validade enunciados jurisprudenciais de exclusiva edição do Supremo Tribunal Federal em que há a 
revelação do entendimento predominante desta Suprema Corte sobre determinada matéria constitucional, após reiteradas decisões acerca do assunto, conforme o art. 103, A da CF/88.

Para se submeter uma súmula à aprovação, pode o STF agir de ofício ou por provocação do Presidente da República, da Mesa do Senado Federal, da Mesa da Câmara dos Deputados, da Mesa da Assembléia Legislativa ou da Câmara Legislativa do Distrito Federal, do Governador de Estado ou do Distrito Federal, do Procurador-Geral da República, do Conselho Federal da Ordem dos Advogados do Brasil, de Partido Político com representação no Congresso Nacional e de Confederação Sindical ou de Entidade de Classe de âmbito nacional. O quorum necessário para a aprovação é de dois terços dos membros do STF, conforme preconiza o art. 103 da Constituição Federal Brasileira.

Após a publicação na imprensa oficial, o preceito jurídico vinculará os demais órgãos do Poder Judiciário e a administração pública direta e indireta, nas esferas federal, estadual e municipal.

As matérias abrangidas pelo instituto em tela deverão ter referência à questão de direito, em que se observe divergência em caráter genérico e reiterado. A súmula se prestará a decidir sobre a constitucionalidade das leis, sobre a melhor interpretação das normas em confronto com os ditames constitucionais, bem como sobre sua exigibilidade ou, nos termos da Carta Magna : “a súmula terá por objetivo a validade, a interpretação e a eficácia de normas determinadas ...” (CF/88, art. 103-A, §1º)

Para não restar dúvida acerca dos objetivos da súmula, merece que seja transcrito os ensinamentos de Marcelo Lamy e Luiz Guilherme Arcaro Conci, em suas reflexões sobre as súmulas vinculantes:

Controvérsia sobre a validade, na seara constitucional, é divergência atinente à constitucionalidade de norma infraconstitucional concreta. Controvérsia sobre a interpretação é desacordo sobre o melhor significado de determinado dispositivo de acordo com os ditames constitucionais. Controvérsia sobre a eficácia é dissenso sobre a coercibilidade jurídico-social de normas determinadas, no tempo e no espaço. (2005, p. 309)

As normas sobre as quais haverá a produção de súmula vinculante necessitam ser palco de controvérsia entre os órgãos judiciários, ou entre esses e a administração pública, e esta discórdia deve ser causa de grave insegurança jurídica e relevante multiplicação de processos sobre questão idêntica.

Delimitaram-se os preceitos legais que a súmula poderá tratar. A obviedade das regras que precisam ter assentado entendimento do Tribunal Supremo serem aquelas que despertam conflitos de interpretação entre os juízes, tribunais e administração pública não foi suficiente para os constituintes derivados deixarem implícito este comando. 
Por certo, procurou-se evitar a incidência de súmulas vinculantes em questões pacíficas, buscando limitar a atividade legislativa do Poder Judiciário para as querelas em que a sociedade se veja em ambiente instável, no qual a divergência existente em torno do dispositivo legal funcione como uma espécie de loteria, uma vez que as sentenças que lhe são decretadas variam em razão da vara, da turma ou da região em que as ações são julgadas.

O julgamento de casos análogos, em que há a mesma lei regulamentando a situação litigiosa, com resultados distintos, leva o jurisdicionado a questionar a isonomia na aplicação legal. Ora, se todos devem ser tratados igualmente perante a lei e as relações jurídicas postas em confronto eram semelhantes, o fato de não ter havido identidade na decisão judicial definitiva faz surgir a possibilidade dos sucumbentes impetrarem recurso extraordinário no Supremo Tribunal Federal, sob a alegativa de violação do princípio constitucional da isonomia, norteador do Estado Democrático de Direito. Deste desentendimento jurisprudencial será originada uma avalanche de ações repetitivas que inundam as prateleiras da Corte Suprema. Em prol da segurança jurídica dos particulares e da celeridade processual, buscou-se, nessa perspectiva, extigüir este cenário no judiciário brasileiro.

O parágrafo $2^{\circ}$ do Art. 103 - A da Constituição Federal de 1988 estatui, in verbis:

$\S 2^{\circ}$ Sem prejuízo do que vier a ser estabelecido em lei, a aprovação, revisão ou cancelamento de súmula poderá ser provocada por aqueles que podem propor a ação direta de inconstitucionalidade.

A súmula vinculante não impedirá a renovação do direito. Será um processo mais dificultoso para se afastar a interpretação vinculada, mas a Constituição prevê essa possibilidade através de revisão ou cancelamento da súmula.

Marco Aurélio Costa Moreira de Oliveira, citado por Enéas Castilho Chiarini Júnior, afirma que:

é certo que a ordem jurídica deve proporcionar aos julgados da Corte Suprema e do Superior Tribunal de Justiça maior eficácia do que às decisões de tribunais de menor hierarquia. No entanto, o efeito vinculante de suas decisões sumuladas não pode ser aceito, se causar paralisia no desenvolvimento de nosso direito e das letras jurídicas do país. (2006, Disponível em: <http://jus2.uol.com.br/ doutrina/texto.asp?id $=4248>$ )

Bem se vê a precipitação das considerações tecidas pelo autor. A súmula não está alheia a entendimentos contrários. Contudo, exige um processo distinto para ser revisada ou cancelada. 
Por fim, para encerrar a exposição sobre esse novo instrumento jurídico, precisa-se mencionar que caso um ato administrativo ou uma decisão judicial contrarie súmula aplicável ou a aplique indevidamente, caberá reclamação ao Supremo Tribunal Federal que, julgando-a procedente, anulará o ato administrativo ou cassará a decisão judicial reclamada, e determinará que outra seja proferida com ou sem a aplicação da súmula, conforme o caso. (Art. 103 - A, § 3º $\mathrm{CF} / 88$ )

\section{Súmula Vinculante e o Livre Convencimento E INDEPENDÊNCIA DO JUIZ}

É impossível imaginar o ato interpretativo em que não haja a consideração das particularidades do caso concreto (Schnaid, 2004, p.276 e 277)

À primeira vista, pode-se extrair desta afirmação o entendimento de que a interpretação inafastável de normas jurídicas é incompatível com a livre convicção e a independência do juiz. Entretanto, uma análise mais profunda faz cair por terra esta compreensão.

Se, no exame das particularidades do caso concreto, o juiz considerar não ser aplicável a súmula vinculante, existe a possibilidade de ser afastada sua incidência motivadamente.

Sobre esta questão, Hans Kelsen pontuou:

A decisão que constitui o precedente apenas pode ser vinculante para a decisão de casos iguais, a questão de saber se um caso é igual ao precedente é de importância decisiva. .... só com base na norma geral que é criada pela decisão com caráter de precedente se pode decidir se dois casos são iguais. (2000, p.278)

O juiz, mesmo estando submetido a aplicar o instituto em tela, procede à interpretação, já que necessita aferir se as especificidades do caso concreto não determinam a não aplicação da súmula.

Para Enéas Castilho Chiarini Júnior, entretanto, a súmula com efeitos ultrapartes viola o livre convencimento do juiz. Em seu dizer:

Como o direito brasileiro adota o sistema do livre convencimento fundamentado do juiz, este não está obrigado a seguir o entendimento das súmulas editadas pelos tribunais, que somente servem como orientação para os juízes, que podem, ou não, acolher tais entendimentos em seus julgados de inferior instância. (2006,

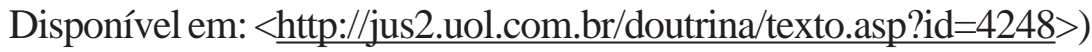


O que se tornou imprescindível foi o respeito à interpretação dada ao STF em todas as circunstâncias em que a súmula possa ser aplicada. Ora, cabe a este tribunal o zelo pelas questões constitucionais e não pode ser considerado excesso a competência que lhe foi dada para dar a melhor interpretação à norma segundo os preceitos constitucionais, para decidir sobre sua constitucionalidade e exigibilidade.

Importante observar que o princípio do livre convencimento do juiz, embora seja corolário do devido processo legal e da independência do magistrado, não deve ser entendido em termos absolutos. A isonomia processual garantida pela súmula justifica a relativização do livre convencimento do juiz quanto à interpretação da norma a ser aplicada. Ressalte-se que subsiste a independência com relação ao julgamento da situação concreta e da interpretação sobre a incidência da súmula.

\section{x Súmula Vinculante e o Princípio da Separação dos Poderes}

Questiona-se a superioridade que a súmula vinculante se posicionou ante a lei. Caso se considere que a norma legal ainda é passível de interpretação, ao passo que a súmula já a engloba, não podendo afastar a interpretação conferida pelo STF, com exceção da possibilidade supracitada, realmente é vislumbrado a sobreposição da súmula ante a norma legal.

Vale a pena diferenciar esses dois preceitos.

Novamente serão aproveitados os ensinamentos dos nobres doutrinadores Marcelo Lamy e Luiz Guilherme Arcaro Conci:

a súmula vinculante constitui enunciado interpretativo de comando normativo preexistente. Não é a súmula quem cria o comando, mas o ato normativo existente... A súmula vinculante, portanto, determinará o significado válido da norma infraconstitucional que está em acordo com os ditames constitucionais hierarquicamente superiores, ou fixará o significado que está em desacordo, segundo entendimento sedimentado em reiteradas decisões anteriores. (2005, p. 314 e 315)

A súmula vinculante, como muito bem exposto, não criará direito material novo, apenas determinará como a norma jurídica deve ser interpretada. No entanto, apresenta os efeitos semelhantes ao da lei: a obrigatoriedade, a abstração e a generalidade, servindo de baliza para os juízes e para os jurisdicionados.

De fato a súmula vinculante carrega todas essas características.

A obrigatoriedade é verificada na vinculação aos órgãos judiciários e à administração pública direta e indireta em todas as esferas e na possibilidade de o 
STF, mediante ter sido provocado por reclamação, anular ato administrativo e cassar decisão judicial se houver a contrariedade de súmula aplicável ou sua aplicação indevida, conforme explicado no Capítulo referente à súmula.

A não existência de destinatário específico ou o fato de não ser dirigido à situação particular consiste na abstração.

Por fim, a generalidade relaciona-se à extensão dos efeitos erga omnes.

Bem nítida é a diferença entre a súmula vinculante e a lei, apesar da igualdade de seus efeitos.

De importante valor para a análise da súmula, ante o princípio da separação dos poderes, é o fato de o referido instituto não constituir limitação material para a elaboração das normas jurídicas pelo Congresso Nacional, restando preservada a competência legislativa do respectivo órgão.

A lei posterior poderá dispor sobre matéria tratada em súmula vinculante, inclusive a revogando, caso regulamente de forma diversa do conteúdo da súmula.

Pelo parágrafo $2^{\circ}$ do art. 103-A da Constituição, infere-se que a súmula vinculante não obsta o exercício da atividade legislativa. Dessa forma, retira-se a idéia de superioridade da súmula perante a lei. A súmula não revoga a lei, nem realiza-se contra legis, apenas obriga que esta seja interpretada de igual maneira do Supremo Tribunal Federal.

Entendimento discrepante a esse serviria de baliza para a corrente doutrinária que indica estar o princípio da separação dos poderes sendo aquebrantado por este preceito, impingindo uma inconstitucionalidade ao instituto em decorrência deste argumento por força deste princípio ter sido eleito pelos constituintes originários como cláusula pétrea.

A tripartição dos poderes, conforme dito alhures, não deve ser interpretada rigidamente. A súmula vinculante compreende um ato de cunho jurídico, a interpretação, com efeitos análogos ao da norma legal, sendo, por tal turno, considerada atividade legislativa.

Entretanto, observou-se que sua inserção no ordenamento jurídico tem o objetivo de fazer com que a atividade judiciária tenha aplicação isonômica em todo o território, seja em qual vara ou tribunal aconteça o julgamento. As particularidades do caso, em existindo demonstração cabal da necessidade de julgamento diferente da hipótese da súmula, possibilitam, fundamentadamente, o afastamento de sua incidência.

Assim, dado que o objetivo do instituto tenha sido a proteção de direitos dos cidadãos, qual seja, o tratamento isonômico, dando-lhes segurança jurídica e conferindo maior eficiência ao Estado, justificável a autorização do Poder Judiciário, excepcionalmente, realizar a atividade legislativa.

A forma não deve ser superior à finalidade para o qual o princípio foi criado.

Deve-se ressaltar que essa extra-atividade judiciária inseriu-se no ordenamento através de Emenda Constitucional. Os próprios representantes do povo pertencentes ao Poder Legislativo que a editaram. 
Importante lembrar novamente que a atividade legislativa não se quedou prejudicada pela súmula vinculante.

Sobre a atividade do Judiciário e a tripartição dos poderes, afirma Mancuso:

Justamente porque dentre nós a tripartição dos Poderes não opera, como visto, como um dogma intransponível, verifica-se que, por vezes, a atuação do Poder Judiciário acaba por projetar reflexos nas searas dos demais. Assim se dá em face do Legislativo, quando uma lei é declarada inconstitucional, e é oficiado o Senado para que promova à supressão do texto indigitado (CF, arts. 102, I, $a$, e 52, X); ou, em face do Executivo, quando é acolhida uma ação direta interventiva (CF, art. 34, VII, c/c art. 36, III); ou mesmo quando a Justiça Eleitoral declara inelegível um governante (Lei 4.737/65, art. 22, I, j); enfim, quando se ordena a inclusão de precatório judicial na ordem cronológica de pagamentos (CF, art. 100). Ocorrências como essas, numa leitura mais apressada, podem induzir a impressão de que o Judiciário configura um supra Poder, mas, a rigor, cuida-se de aplicação do sistema de freios $e$ contrapesos, a impedir a exarcebação de um Poder em face dos demais. E, depois, não poderia mesmo ser diferente, porque a lei obriga a todos, indistintamente, mas é o Judiciário o seu intérprete e aplicador, em caráter de definitividade. (2001, p. 94)

A súmula vinculante apenas teve como propósito conferir maior eficácia à prestação jurisdicional do Estado. A impossibilidade do legislador abarcar todas as situações rotineiras, sua necessidade de, na maior parte das vezes, editar normas com teor genérico para abranger o maior número de casos possíveis gerou ações repetitivas que elevam sobremaneira o número de processos no Judiciário, em que uma interpretação definitiva da norma poderia findar ou ao menos diminuir o problema.

Não parece correto submeter os jurisdicionados a longos períodos para julgamento de ações que por fim terminarão no Supremo Tribunal Federal, que aplicará o seu entendimento sobre a matéria.

Se a atividade legislativa do Poder Legislativo é complementada pelo Poder Judiciário, sem prejuízo para seu exercício, não justifica apontar violação da tripartição dos poderes.

\section{$x$ Considerações Finais}

Restou comprovado que a súmula vinculante não ofende o princípio da separação dos poderes. 
O moderno entendimento deste princípio não considera cada poder como um compartimento estanque. A separação dos poderes, interpretada com ressalvas atualmente, possibilita o exercício de atividades atípicas pelos outros poderes.

Deve ser destacada a finalidade para a qual o princípio foi criado, qual seja a proteção das liberdades individuais. Posteriormente, seus objetivos foram ampliados, abrangendo a intenção de dar maior eficiência ao Estado.

A súmula vinculante foi criada para que a atividade legislativa seja prestada isonomicamente e com maior agilidade, proporcionando segurança jurídica aos cidadãos.

Outro ponto em que se demonstra a não violação do princípio da separação dos poderes é o fato de a atividade legislativa não se mostrar comprometida pelo discutido instituto, por a súmula não constituir limitação material à lei e por poder ela ser revogada por norma legal posterior.

Com relação à livre convicção e independência do juiz, também foi demonstrada a compatibilidade da súmula com este princípio.

Subsiste a atividade interpretativa do juiz, que necessita aferir no caso concreto através do exame de suas particularidades se a súmula vinculante é aplicável ou não. Em caso de incidência da súmula, haverá a obrigatoriedade da observância da interpretação do Supremo Tribunal Federal.

O princípio do livre convencimento e da independência do juiz deve ser relativizado frente à importância da aplicação isonômica da lei para os jurisdicionados.

A súmula vinculante possui inúmeros outros pontos de discordância. O presente trabalho se propôs a responder apenas as indagações sobre a existência de afronta ao princípio da separação dos poderes e de limitação do livre convencimento e independência do Juiz. Não é possível, baseado apenas neste estudo, declarar a súmula constitucional, dado que os outros questionamentos quedaram-se sem resposta.

\section{REFERÊNCIAS BibliográficAS}

DALLARI, Dalmo de Abreu. Elementos da teoria geral do Estado. São Paulo: Saraiva, 2003.

MANCUSO, Rodolfo de Camargo. Divergência jurisprudencial e súmula vinculante. São Paulo: Revista dos Tribunais, 2001.

MORAES, Alexandre de. Direito Constitucional. São Paulo: Atlas, 2003.

KELSEN, Hans. Teoria pura do direito. São Paulo: Martins Fontes, 2000.

SCHNAID, David. Filosofia do direito e interpretação. São Paulo: Revista dos Tribunais, 2004.

TAVARES, A. R. LENZA, P. ALARCÓN, P. J. L. Reflexões sobre as súmulas vinculantes. In: LAMY, M. CONCI, L.G.A. Reforma do Judiciário analisada e comentada. São Paulo: Método, 2005. 
VIDAL, Jânio Nunes. Democracia e constitucionalismo: Princípio da maioria e legitimidade da jurisdição constitucional. 2005. Dissertação (Mestrado em Ordem Jurídica Constitucional) - Universidade Federal de Fortaleza, Fortaleza, 2005. CHIARINI JÚNIOR, Enéas Castilho. A inconstitucionalidade da súmula de efeito vinculante no direito brasileiro. Disponível em: <http://jus2.uol.com.br/ doutrina/texto.asp?id=4248> Acesso em: 22 maio 2006.

\section{STARE DECISIS: AN ANALYSIS ACCORDING TO THE PRINCIPLES OF SEPARATION OF POWERS AND FREE CONVINCEMENT AND INDEPENDENCE OF THE JUDGE.}

Abstract: This study focuses Brazil's new juridical institute, called 'súmula vinculante' (stare decisis). It will be analyzed under the perspective of the principles of separation of powers, the free conviction and the independence of the judge.

Keywords: Stare decisis. Abridgment of law. Juridical principles. 